\title{
Reflections of Affect in Studies of Information Behavior in HIV/AIDS Contexts: An Exploratory Quantitative Content Analysis ${ }^{1}$
}

\author{
Heidi Julien ${ }^{\mathrm{a} *}$, Ina Fourie ${ }^{\mathrm{b}}$ \\ ${ }^{a}$ Visiting Professor, Department of Information Science, University of Pretoria \\ IT Building 6-65, Lynnwood Road, Pretoria 0002, South Africa \\ Department of Library \& Information Studies, University at Buffalo, 526 Baldy Hall, \\ Buffalo, NY 14260 United States \\ ${ }^{\mathrm{b}}$ Department of Information Science, University of Pretoria, IT Building 6-65, Lynnwood Road, \\ Pretoria 0002, South Africa \\ *Corresponding Author \\ Email address: heidijul@buffalo.edu (H. Julien)
}

\begin{abstract}
Information seeking and use are critically important for people living with HIV/AIDS, and for those who care for people with HIV/AIDS. In addition, the HIV/AIDS context is characterized by significant affective or emotional aspects, including stigma, fear, and coping. Thus, studies of information behavior in this context should be expected to take account of emotional variables. In information behavior scholarship, emotional variables have been marginalized in favor of a focus on cognitive aspects, although in recent years greater attention is being paid to the affective realm. This exploratory study used quantitative content analysis to explore the degree to which information behavior studies across a range of disciplines actually include affect or emotion in their analyses. Findings suggest that most studies pay little or no attention to these variables, and that attention has not changed over the past 20 years. Those studies that do account for emotion, however, provide excellent examples of information behavior research that can lead the way for future work.
\end{abstract}

\footnotetext{
${ }^{1}$ An early version of this paper was presented at the 2013 Information: Interactions and Impact Conference in Aberdeen, U.K.
} 


\section{Introduction}

Human immunodeficiency virus infection / acquired immunodeficiency syndrome (HIV/AIDS) presents a complex array of health and social challenges, and is arguably one of the most significant issues of our time. The HIV/AIDS experience is global, affects very large numbers of people, has significant impacts on societies at large, and has generated increasing expectations for families and communities to supplement the care provided by health and palliative care infrastructures (Coleman \& Toledo, 2002; Dancy \& Dutcher, 2007; Fourie, 2012; Schnall, Cimino, Currie, \& Bakken, 2011; Schnall, Cimino, \& Bakken, 2012). Governments around the world are greatly concerned about HIV/AIDS (Berkelman, 2012; Holtgrave, 2002; Swartz \& Roux, 2004), and have invested significant sums into prevention and treatment.

Information exchange is fundamental to meeting these challenges. Optimizing information exchange by understanding people's information behaviors and the barriers to successful information experiences has been the focus of information behavior, a substantial field of research in Information Science, as well as in other disciplines. Information behavior is an encapsulating term for all human behavior related to information, such as recognizing and expressing information needs, information seeking, information searching, information retrieval, information encountering, browsing, information avoidance, information use, and unawareness

of information needs (Case, 2012; Wilson, 1999). Information behavior scholarship is concerned with all contexts of human interaction, including workplaces, learning environments, and daily life situations. Daily life contexts include decision-making for personal matters, engagement with other people and institutions, and dealing with health challenges. The intention of information behavior research is to inform the design of information retrieval systems and 
information related interventions such as information communication, information provision and patient education (Hepworth, 2007; Johnson \& Case, 2012). Information behavior traditionally has been approached from a cognitive viewpoint, with an emphasis on people's cognition with respect to their information interactions. More recently, attention has expanded to include attention to affective aspects of information behavior; that is, to begin to understand how people's emotions play into their thinking about, finding, and using information. As Albright notes, emotions may well play a stronger role in decision-making than cognition (Albright, 2010).

Studies of information behavior in healthcare contexts are drawing increasing attention to requirements for information provision, information literacy, information exchange, information sharing and potential of the Internet (Case, 2012; Johnson \& Case, 2012; Kalichman et al., 2012). The HIV/AIDS context, however, is relatively unexplored among information behavior scholars. Yet, this context provides a rich opportunity to understand information behavior from a holistic perspective. Perhaps more than any other life-threatening disease, HIV/AIDS is associated with fear, emotional distress, emotional needs, stigma, shame, discrimination, and social injustice (Blumberg, 2000; Emeka, 2008; Mill, Edwards, Jackson, MacLean, \& ChawKant, 2010; Reeves 2001; Sandstrom, 1996; Veinot, 2009). Coping is a significant aspect of HIV/AIDS (Kalichmanet al., 2005; Polinko, Bradley, Molyneuax, Lukoff, \& Erlin, 1995). People with HIV/AIDS diagnoses face the physical, emotional, and psychological challenges of dying and death, self-care, and disclosing their disease status to others (Chou, Holzemer, Portillo, \& Slaughter, 2004; Huber \& Cruz, 2000; Marhefka et al., 2011; Nokes \& Nwakeze, 2005; Shelley et al., 2006). Apart from support for physical care, people living with HIV/AIDS require 
a non-judgemental and supportive attitude from others. Kalichman et al., (2012) and Benotsch, Kalichman, and Weinhardt (2004) note the vulnerability of people living and coping with HIV/AIDS. In addition, many people in supporting positions are affected by HIV/AIDS, such as families, nurses, doctors, case managers, caregivers, and teachers (Bitso \& Fourie, 2012; Harris, Veinot, \& Bella, 2010; Petros, 2012). Even caregivers working with children face stigmatization (Coleman \& Toledo, 2002).

There is increased emphasis on acknowledging emotion in discussing HIV/AIDS (Finset, 2012) and in considering emotion in healthcare information and educational interactions (Danielle Lottridge \& Chignell, 2012). Emotion can be implied by words associated with HIV/AIDS such as support and care-giving (Petros, 2012), desire for information, need for encouragement and support, and coping (Kalichman et al., 2003). This is consistent with the increasing interest in affect and emotion in information behavior work more generally (Fourie, 2012; Julien, McKechnie, \& Hart, 2005; Danielle Lottridge \& Chignell, 2012; Nahl \& Bilal, 2007; Schmidt \& Stock, 2009; Sheih, 2011; Tenopir, 1994; Thelwall, Wilkinson, \& Uppal, 2010). In this paper, we use the terms "affect" and "emotion" interchangeably, although there are differing interpretations. For example, Wetherell (2012) states that affect is "embodied meaningmaking...understood as human emotion" (Wetherell, 2012, p. 4). Albright suggests that "affect is the conscious experience of an emotion" (Albright, 2010, p. 100). In general discourse, however, these terms are used synonymously.

Bridging the digital divide and improving information retrieval systems and educational interventions in healthcare requires a deepened understanding of information behavior, but not 
only from a systems or cognitive point of view (Ingwersen \& Järvelin, 2005). It is increasingly recognized that scholarship should also focus on people, and their emotions and affective experiences (Nahl \& Bilal, 2007). People react emotionally to information (Preece, 2007) and emotions impact on understanding, internalisation, learning, and coping. As Mosha and Manda (2012) state, "even though information is necessary to bring about behaviour change, it is not sufficient on its own, it is also necessary to take into consideration other determinants such as experiences, emotions and social-cultural environment" (Mosha \& Manda, 2012, p. 514). The importance of affect has often been noted in the information behavior literature (Dervin \& Reinhard, 2007; Julien, et al., 2005; Nahl \& Bilal, 2007), to such an extent that Nahl (2007), Albright (2010), and Bilal (2005) refer to an emerging "affective paradigm" in information behavior research. Despite this apparent embracing of affect as a critical aspect of information behavior, the degree to which scholars are actually exploring emotional variables is uncertain (Julien, Pecoskie, \& Reed, 2011).

A spectrum of people affected by HIV/AIDS is evident in reports on information behavior and HIV/AIDS, including young people (Buseh, Glass, McElmurry, Mkhabela, \& Sukati, 2002; Chanda, Mchombu, \& Nengomasha, 2008; Dupas, 2011; Eriksson, Sonesson, \& Isacsson, 1997; Fisher, 2012; Fisher, Fisher, Bryan, \& Misovich, 2002; Flicker et al., 2004) as well as old people (Henderson et al., 2004; Kalichman et al., 2005; Petros, 2012), men as well as women (Hong, Li, Fang, Lin, \& Zhang, 2011; Huber \& Cruz, 2000; Hutchinson et al., 2007; Ilo \& Adeyemi, 2010; Kalichman et al., 2001), and patients as well as caregivers (Adetoro, Oyefuga, \& Simisaye, 2010; Coleman \& Toledo, 2002; Hogan \& Palmer, 2005). Students especially feature strongly in information behavior studies (Agboola, 2012; Ajayi \& Omotayo, 2010; Goh, 1993; Heuttel \& 
Rothstein, 2001; Hong, Li, Mao, \& Stanton, 2007). These examples from the literature studied provide context for the seriousness of the HIV/AIDS problem, and the scope of research in the area. The range of study participants (young and old or people in different roles) demonstrate that this is a disease and social challenge affecting people of all ages and in a variety of roles. They can all benefit from a deeper understanding of affect in information behaviour in dealing with a highly emotionally and affect laden disease affecting very large numbers of people. Although differences between young and old, male and female and taking on different roles have been noted in information behaviour studies e.g. as reported in the monograph by Case (2012) our intention is not to dwell on this. It should also be noted that not all articles studied are cited in the paper; references are only made to those we cite as an example or to strengthen an argument.

It is argued that information might make a difference in coping with HIV/AIDS (Kalichman, 2007; Kalichman et al., 2003, 2005, 2006b; Mo \& Coulson, 2008; Reeves, 2000, 2001), in the prevention and reduction of HIV/AIDS (Albright \& Kawooya, 2005; Blumberg, 2000), motivation to adhere to treatment (Cornman, Schmiege, Bryan, Benziger, \& Fisher, 2007; Johnson \& Case, 2012), motivation to change sexual behavior (Fisher, 2012), and in promoting HIV testing (Davis et al., 2011). Substantial interest is reported in use of the Internet as tool for information seeking and for delivering educational interventions, as well as for information dissemination and supporting people in coping with HIV/AIDS (Kalichman, 2007; Kalichman, Weinhardt, Benotsch, \& Cherry, 2002; Kalichman et al., 2003, 2005, 2006a, 2006b, 2012; Kalichman, Picciano, \& Roffman, 2008; Mayben \& Giordano, 2007; Mo \& Colson, 2008; Reeves, 2000; Rice, Monro, Barman-Adhikari, \& Young, 2010; Robinson \& Graham, 2010; 
Samal et al., 2011; Smith, 2004, 2011) and for bridging the digital divide (Benotsch, et al., 2004; Kalichman et al., 2002, 2003). "For patients with chronic and life-threatening conditions, the Internet can serve as a source of hope, social support, and empowerment" (Benotsch et al., 2004, p. 1004).

African countries are heavily affected by HIV/AIDS, and are therefore proportionally highly represented in studies on information behavior and HIV/AIDS (Abba, Leleu-Merviel \& Hachimi, 2006; Arinola \& Adekunjo, 2011; Adetoro et al., 2010; Agboola, 2012; Albright, 2007; Bastien, Leshabari, \& Klepp, 2009; Buseh et al., 2002; Chanda et al., 2008; De Walque, 2007; Dube, 2005; Edewor, 2010; Froelich \& Vazquez-Alvarez, 2009; Kanyengo, 2010; Manda, 2006; Mansoor \& Dowse, 2007; Mosha \& Manda, 2012; Ntombela, Stilwell, \& Leach, 2008; Nwezeh, 2008; Odusanya \& Bankole, 2006; Uhegbu \& Okereke, 2006; Ybarra, Kiwanuka, Emenyonu, \& Bangsberg, 2006; Yousafzai, Edwards, D'Allesandro, \& Lindstrom 2005). Concerns for information needs and information seeking are, however, also reported in studies focusing on the United States (Amico et al., 2009; Fogel, 2007; Stroman, 2005), Asia and India (Bhattacharya, Cleland, \& Holland, 2000), Peru (Busse \& Curioso, 2010), Sweden (Eriksson, et al., 1997), Nicaragua (Espinoza et al., 2011), Canada (Harris et al., 2010; Veinot, Harris, Bella, Krajnak, \& Rootman, 2006; Veinot, 2009), China (Lau \& Tsui, 2012; Liu et al., 2010; Sun et al., 2010), Taiwan (Lu, Palmgreen, Zimmerman, Lane, \& Alexander, 2006), Spain (Caro-Murillo, Castilla, \& Del Amo, 2010), Eastern Mediterranean region (Tawilah, Tawil, Bassiri, \& Ziady, 2002), and Iran (Yazdi et al., 2006). 


\section{Problem Statement}

Despite the significance of the HIV/AIDS context, and although HIV/AIDS is strongly associated with emotion, and although a number of studies have been reported on information behavior and HIV/AIDS, there is doubt about how strongly affect actually is reflected in research on information behavior and HIV/AIDS. Studies of information behavior seem to focus mostly on information retrieval systems such as the Internet, World Wide Web, health information systems and helplines, as well as cognitive issues such as the evaluation of information or information sources and decision-making (Busse \& Curioso, 2010; Kalichman et al., 2006a). The research question asked in this study, then, is: To what extent is affect depicted in research reports on information behavior and HIV/AIDS?

\section{Methods}

To determine the extent (i.e. major, minor, pheripheral, not at all) and how affect features in studies of information behaviour) an exploratory quantitative content analysis was selected to examine the treatment of affect in studies of information behavior relating to the HIV/AIDS context. Quantitative content analysis is "a research technique for making replicable and valid inferences from texts (or other meaningful matter) to the contexts in their use" (Krippendorf, 2013, p. 24). This method is a standard one in the social sciences, and in the area of information behavior several authors have applied content analysis, including Aharony (2012), Bar-Ilan (2000), Fourie (2012), Julien and Given (2003), Järvelin and Vakkari (1993), Julien (1996), Julien et al. (2005), Julien et al. (2011), and White and Marsh (2006).

The articles included in the analysis were identified by searching in the health sciences and library and information science fields. It was intended as a scoping review to determine the status of depth with which affect is treated in studies of information behaviour and HIV/AIDS; it was 
not intended as a systematic review e.g. as discussed by Gough, Olivier and Thomas (2012). Databases searched included:

- $\quad$ AIDS and Cancer Research Abstracts

- $\quad$ Cumulative Index to Nursing and Allied Health Literature (CINAHL)

- $\quad$ ISI Web of Science

- $\quad$ Library and Information Science Abstracts (LISA)

- $\quad$ Library, Information Science \& Technology Abstracts (LISTA)

- Library Literature

- Medline

- $\quad$ PsycARTICLES

- PsycInfo

The search strategy used, with slight adaptations if necessary for specific databases, was:

(HIV OR Acquired Immune Deficiency Syndrome OR Acquired Immunodeficiency

Syndrome OR Acquired Immuno Deficiency Syndrome) AND Information

All terms had to appear in the title of publications. The intention with using a broad concept information - was that it will also picking up "information seeking", "information searching", "information needs", "information avoidance" and other terms related to information behaviour/behavior. At this stage of the scoping review we did not want to include other related terms of value such as "social media" or "social networks" or "websites" or the Internet. By searching in the titles only, we wanted to select scholarly articles that deal very specifically with our topic. 
We imposed no publication date limit, but limited the analysis to articles available in full text written in English. We also limited the sample to user-focused studies, and thus excluded systems-oriented approaches including articles focused on information resources and information systems per se, and information services and information provision including services provided by libraries, information service providers and information resource centres. We also excluded articles that focused on the prevalence of HIV/AIDS and patient information, bibliometric studies, information management, training programs on HIV/AIDS, mass media campaigns (including their effectiveness), and publications on the effect of information resources except when dealing with issues of coping or motivation. The final sample included 105 articles which met our criteria for inclusion, and were traceable. The authors where in each other's physical presence when initially selecting the articles for the content analysis.

The analyses proceeded with two coders. Pilot coding found a high level of agreement in application of content analysis categories, and careful discussion ensured that subsequent independent coding produced reliable analyses. The detailed forms completed by each reviewer and the fulltext publications were at all times available to both authors for verification if needed. Analyses focused on relative treatment of affect in each article. Four levels were considered: major (the author(s) explicitly addressed and discussed some aspect of affect), minimal (affect was mentioned in passing, without discussion of the meaning or implication of affective factors), peripheral (aspects of affect were included in the research, but other than stating the research results, there was no real discussion of affect) and none (i.e. no mention of terms related to affect and emotion). From the articles selected and reviewed, those providing major coverage were considered in more detail to (1) determine what can be learned and, (2) to determine how this can 
be used to promote better, wider and more in-depth coverage of affect in studies of information behaviour in HIV/AIDS.

\section{Results and Discussion}

The articles included in the data set were published between 1993 and 2012. When coding, a large number of terms in the sample of literature were identified as evidence of attention to affect. These included (but were not limited to):

- $\quad$ Stigmatise, stigmatisation

- $\quad$ Coping, self-efficacy

- $\quad$ Self-concept - used in affective terms

- $\quad$ Motivation

- $\quad$ Feelings such as depression, frustration, satisfaction, dissatisfaction

- $\quad$ Trust, mistrust

- $\quad$ Sense-making and feelings important to sense-making

- $\quad$ Psychological distress

- $\quad$ Attitudes

- $\quad$ Prejudice

- Compassion

- $\quad$ Fear

- $\quad$ Respect, etc.

The analyses revealed a range of author disciplines represented in the sample. Discipline was determined by affiliation of the first author of each article. The health disciplines comprised the largest proportion of the literature $(\mathrm{n}=41 ; 39 \%)$. This group included Medicine (Psychiatric and Behavioral Medicine, Infectious Diseases, and Internal Medicine and Primary Care) $(n=20$; 
19\%); Nursing ( $\mathrm{n}=7 ; 6.7 \%)$; Public health $(\mathrm{n}=5 ; 4.8 \%)$; and Others (including Pharmacy, Health Behavior, Pharmacology, Health Intervention and Prevention, Biomedical Informatics, and Health as a general category) $(n=9 ; 8.6 \%)$. The next largest proportion of literature was from Information Science and Librarianship $(\mathrm{n}=25 ; 24 \%)$. Author affiliation was not indicated or unknown in 10 articles (9.5\%). Eight articles came from Psychology (7.6\%), seven (6.7\%) from Communications (Media, Information and Telecommunication; Communication and Information Studies; Journalism and Mass Communication), six (5.7\%) from Social Work, three (2.9\%) from Education, and two (1.9\%) from Sociology (including Sociology; and, Anthropology and Criminology). Authors from Other disciplines contributed six articles (4.8\%); those disciplines included Statistics, Economics, Counselling and Human Development, Justice Studies, and Behavioral Science. These findings give an indication of researchers setting the tone and with which disciplines collaboration and partnerships in further research should be fined.

Treatment of affect was coded into one of four categories: none (no mention of affect), peripheral (brief mention of affect with no discussion), minimal (mention of affect without significant discussion of meaning or implications of affective aspects), and major (some aspects of affect explicitly addressed and discussed). The largest proportion of articles treated affect peripherally $(n=38 ; 36.2 \%)$; the second largest proportion $(n=34 ; 32.4 \%)$ did not mention affect at all (i.e., were coded "none"); 24 (22.9\%) articles were coded as major; and 9 articles (8.5\%) were coded as minimal. 
In those articles with peripheral attention to affect, some aspect of affect was mentioned in the title, or literature review, or even measured, but then not discussed. One study (\#9), ${ }^{2}$ for example, quoted directly from the landmark Nahl and Bilal (2007) text, noting that work in information science has started to include affective variables, but then did not further pursue those variables. Another study (\#15) noted the value of the Internet as a source of support and hope and also as a source of emotional distress resulting from negative information. The methods section of this article indicated that the authors had surveyed participants with an instrument that assessed hopes, optimism, and efficacy beliefs regarding anti-HIV therapies; however, none of these results were discussed. The introduction to article \#19 refers to the emotional support provided by close social relationships, including those fostered by online communications. That introduction also refers to the stigmatization of those with HIV/AIDS, yet nowhere else in the article is affect mentioned. The introduction to article \#39 notes that people can fear becoming immobilized by negative information, yet the authors do not pick up that thread in their later discussion. In article \#53, the authors use the term "coping" in the title and measure coping in their empirical research, but that concept is not defined in affective terms. It is operationalized as active information-seeking. This seems to be a particularly superficial approach to a concept as complex and affect-laden as "coping”.

Papers that treated affect in a minimal way included article \#31, in which affect was a major aspect of findings from interviews with HIV/AIDS infected youth; terms such as "fear," “overwhelming," and "worry" were used by these participants when they discussed their information seeking. These terms were quoted by the study authors; however, these aspects of

\footnotetext{
${ }^{2}$ When specific articles from the data set are mentioned, they are identified by the unique identifier assigned to each article.
} 
the participants' reports were not picked up by the authors in their discussion. Indeed, those studies that analyzed some affective aspects of information behavior, such as depression, which did not then go on to pick up discussion of those variables, were puzzling. These examples beg the question: Why are authors seemingly loathe to focus on these important aspects of information behavior or to take up careful examination of affect, especially when they admit to the existence of these variables?

As noted above, about one in five articles in the sample treated affect in a major way. This subset of the literature is that which can point the way for future work. A good example is article \#11, which focuses on patient-clinical communication, a concept which was rated, among other variables, on aspects such as respect, patient comfort, and expressions of care and concern. The authors, whose disciplinary affiliation is unknown, report on interviews with patients that focus on affect, including fear of asking questions, and issues of trust and confidence in clinicians. Article \#17, in which the first author comes from Statistics, focused entirely on affective responses to messages about HIV/AIDS. These authors conclude by stating that their findings "suggest that inclusion of noncognitive variables in models of HIV-risk behavior may increase the predictive value of these models. In our view, recognition of the influence of noncognitive factors would complement rather than contradict the importance of social-cognitive variables"3 (Carey et al., 2000, pp. 9-10). Another example is article \#36 (Harris et al., 2010), which refers to an early important text in information behavior coming from Information Science (Harris \& Dewdney, 1994), where the importance of emotional support in information provision is emphasized. In the article analyzed for this study, interviews with HIV/AIDS patients included

\footnotetext{
${ }^{3}$ We provide direct quotes only from articles in the sample coded as treating affect in a major way. Since this subset of the sample is being held up as exemplary, citations for these quotes are provided and they are included in the reference list at the end of this article.
} 
discussions of stigma and shame, and the authors note the importance of "expressions of care" (p. 136) by information providers. They conclude that information seekers need to trust information providers, and that trust is expressed primarily in emotional terms. These authors are from Information Science.

Kalichman and colleagues, from Medicine, have published a series of studies, many of which were included in our sample. One of these (\#55) reports on a study that tested social support and affective depression. In the results section of the article, the authors state "Confirming the study hypotheses, we did observe significant increases in social support among individuals in the Internet skills group that were sustained over 9 months and less affective depression at the 6month follow-up. Our conceptual model suggests that these effects are the product of the intervention and the ongoing effects of health and social support use of the Internet. These findings suggest that assisting people living with HIV/AIDS in accessing and effectively using the Internet can impact on at least some aspects of emotional well-being" (Kalichman et al., 2006a, p. 553). Another example, article \#89, focused on how internet use helps people with HIV/AIDS to cope. The authors' emphasis is very much on affective aspects of this information behavior, such as stigmatization, hope, encouragement, fear, confidence, regrets, and depression.

Sandstrom (1996), from Sociology, Anthropology, and Criminology, provides another example from this subset of articles focusing on affect as a major theme. This article (\#98) reports on the use of peer support groups by gay men with HIV/AIDS. Sandstrom notes that "those men who participated in support groups on a long-term basis (i.e. one year or more) were...most interested 
in receiving and exchanging emotionally-oriented forms of support, such as empathy, acceptance and camaraderie" (p. 51).

Veinot had seven articles included in our sample, and is an outstanding example of a researcher in Information Science who focuses on affective variables in information behavior, specifically in the HIV/AIDS context. For example, in article \#115 (Veinot, 2010) she notes that "informational and emotional support often occur together in interactions and can be difficult to separate" (p. 876). She notes that "the lack of information was extremely stressful...for some, the 'vacuum of information' becomes a place in which fear dominated their thoughts" (p. 888). A third example from this author (article \#117) concludes, "Our preliminary results reinforce the need to attend to the affective dimensions of information seeking, particularly in health issues...our study participants reported many emotional reactions to information relevant to their health...the participants' comments demonstrate the high value they place on compassion, responsiveness, and empathy in those from whom they seek information and their negative reactions when they feel ignored or disregarded. Indeed, feeling unsupported by an information provider can lead participants to doubt the information that they receive" (Veinot et al., 2006, p. 285). Clearly, this author is exploring aspects of information behavior that have significant implications for theory-building and for information services provision.

We looked for trends in the sample of literature analyzed here without success; certainly no statistically significant trends were discernible. However, it can be said that there clearly is little evidence for emphasis on affect generally in the Health disciplines and in Information Science. From this data set, it appears that there is more consideration of affect in information behavior 
work coming from Communications and from Social Work. In addition, there are no apparent trends over time; i.e., despite calls for increased attention generally on affect in information behavior (Nahl \& Bilal, 2007), between 1993 and 2012 there was no increase in attention to affective variables in our data set. This finding, however, is consistent with that found for information behavior research overall conducted in Information Science between 1999 and 2008 (Julien et al., 2011).

\section{Conclusion}

HIV/AIDS presents significant challenges to millions of people worldwide. It affects people of all ages and ethnic groups, at all social levels. People in a wide spectrum of positions are affected by this disease, including patients, family members, healthcare workers, caregivers, government agencies, etc. Often, people with HIV/AIDS face multiple related diseases, disorders, and disabilities. Despite these widespread effects, to date relatively little research has been done on HIV/AIDS and information behavior per se. In addition, the research existing in this area barely scratches the surface of the immense potential to explore this particular health context. Findings are scattered and relevant to isolated settings, they cannot be generalized, and there has been little theory-building to date. Regrettably, many studies appear to "dance" around emotion or affect. Scholars appear fearful of treading into affective territory, even when they acknowledge its importance. Is the legacy of the "cognitive paradigm" of information seeking so entrenched that scholars are unable to expand their research horizons to include affect? Are affect-related variables too complex to parse? Whatever the challenges, a subset of the sample of studies we analysed (i.e. those coded as focusing in a major way on affect) demonstrates the immense potential to contribute to scholarship that expands understanding of information behavior. There is much work to be done, but there are scholars who are leading the way. 
Therefore, there is significant potential for collaboration, between researchers from disparate but interested disciplines, and between researchers and practitioners (i.e., information service providers). Scholars in Information Science must look to other disciplines, such as Anthropology and Psychology, to enhance their future work. Empirical work could include systematic data collection from the various stakeholders in the HIV/AIDS context (including policy makers, educators, healthcare workers, information service providers, patients, families, and significant others). A collateral benefit of data collection is that it can stimulate awareness of issues that need to be addressed by information services. It is possible that with more focused, interdisciplinary scholarship, an exploratory model of affect in information behavior in the HIV/AIDS context may be developed. Finally, the current study demonstrates clearly that scholars in all disciplines must increase their efforts to consider affect in analyses of information behavior in their empirical work. For those charged with preparing future information professionals, this study underlines the responsibility for ensuring that service providers are trained to have a clear understanding of the ways in which affective variables play into information behavior.

\section{References}

Abba, S., Leleu-Merviel, S., \& Hachimi, E. M. A. (2006). Identification of the information needs of African populations about the AIDS problem. Canadian Journal of Information and Library Science, 30, 91-91.

Adetoro, N., Oyefuga, A. B., Simisaye, A. O. (2010). Persons with HIV in Ijebu-Ode, Nigeria: Self-concept and information needs. Chinese Librarianship, 29, 1-1. 
Agboola, I. O. (2012). Undergraduate student awareness of HIV/AIDS and information needs: A study of University of Agriculture, Abeokuta, Nigeria. PNLA Quarterly, 76, 126-135.

Aharony, N. (2012). Library and Information Science research areas: A content analysis of articles from the top 10 journals 2007-8. Journal of Librarianship and Information Science, 44(1), 27-35.

Ajayi, N. A., \& Omotayo, B. O. (2010). Challenges of HIV/AIDS to undergraduate students: The librarian's reaction. International Journal of Library and Information Science, 2(5), 8894.

Albright, K. (2007). HIV/AIDS information seeking and healthcare communications in SubSaharan Africa. IFLA Conference Proceedings, 1-13.

Albright. K. (2010). Multidisciplinarity in information behavior: Expanding boundaries or fragmentation of the field? Libri, 60, 98-106.

Albright, K. S., \& Kawooya, D. (2005). The role of information in Uganda's reduction of HIV/AIDS: Individual perceptions of HIV/AIDS information. Information Development, 21(2), 106-112.

Amico, K. R., Barta, W., Konkle-Parker, D. J., Fisher, J. D., Cornman, D. H., Shuper, P. A., \& Fisher, W. A. (2009). The information-motivation-behavioral skills model of ART adherence in a Deep South HIV plus clinic sample. Aids and Behavior, 13(1), 66-75.

Arinola, A. A., \& Adekunjo, O. A. (2011). Analysis of HIV/AIDS information awareness and effectiveness among artisans in Ogbomoso, Oyo State, Nigeria. Library Philosophy and Practice. Retrieved from http://unllib.unl.edu/LPP/arinola-adekunjo.htm

Bar-Ilan, J. (2000). The Web as information source on informetrics? A content analysis. Journal of the American Society for Information Science, 51(5), 432-443. 
Bastien, S., Leshabari, M. T., \& Klepp, K. I. (2009). Exposure to information and communication about HIV/AIDS and perceived credibility of information sources among young people in northern Tanzania. Ajar-African Journal of Aids Research, 8(2), 213-222.

Benotsch, E. G., Kalichman, S., \& Weinhardt, L. S. (2004). HIV-AIDS patients' evaluation of health information on the internet: The digital divide and vulnerability to fraudulent claims. Journal of Consulting and Clinical Psychology, 72(6), 1004-1011.

Berkelman, R. (2012). The United States government's response to HIV/AIDS today: 'Test and treat' as prevention. Journal of Public Health Policy, 33(3), 337-343.

Bhattacharya, G., Cleland, C., \& Holland, S. (2000). Knowledge about HIV/AIDS, the perceived risks of infection and sources of information of Asian-Indian adolescents born in the USA. AIDS Care, 12(2), 203-209.

Bilal, D. (2005). Children's information seeking and the design of digital interfaces in the affective paradigm. Library Trends, 52(2), 197-208.

Bitso, C., \& Fourie, I. (2012). An investigation of information-seeking behaviour of geography teachers for an information service intervention: the case of Lesotho. Information Research, 17(4) paper 549. Retrieved from http://informationr.net/ir/17-4/paper549.html

Blumberg, S. J. (2000). Guarding against threatening HIV prevention messages: An informationprocessing model. Health Education \& Behavior, 27(6), 780-795.

Buseh, A. G., Glass, L. K., McElmurry, B. U., Mkhabela, M., \& Sukati, N. A. (2002). Primary and preferred sources for HIV/AIDS and sexual risk behavior information among adolescents in Swaziland, Southern Africa. International Journal of Nursing Studies, $39(5), 525-538$. 
Busse, P., \& Curioso, W. H. (2010). Internet use and the network composition of people living with HIV/AIDS in an urban area in Peru. Aids and Behavior, 14, 1371-1375.

Carey, M. P., Braaten, L. S., Maisto, S. A., Gleason, J. R., Forsyth, A. D., Durant, L. E., \& Jaworski, B. C. (2000). Using information, motivational enhancement, and skills training to reduce the risk of HIV infection for low-income urban women: A second randomized clinical trial. Health Psychology, 19(1), 3-11.

Caro-Murillo, A. M., Castilla, J., \& Del Amo, J. (2010). Epidemiology of HIV infection in immigrants in Spain: Information sources, characteristics, magnitude and tendencies. Gaceta Sanitaria, 24(1), 81-88.

Case, D. O. (2012). Looking for information: A survey of research on information seeking, needs, and behavior (3rd ed.). Bingley: Emerald Group Publishing.

Chanda, M., Mchombu, K., \& Nengomasha, C. (2008). The representation of HIV/AIDS in the media and its impact among young people in Namibia: A study of Windhoek and Katima Mulilo. Information Development, 24(3), 188-203.

Chou, F. Y., Holzemer, W. L., Portillo, C. J., \& Slaughter, R. (2004). Self-care strategies and sources of information for HIV/AIDS symptom management. Nursing Research, 53(5), $332-339$.

Coleman, M., \& Toledo, C. (2002). A study of the relationship between child care providers' use of HIV/AIDS information sources, knowledge of HIV/AIDS, and attitudes toward caregiving policies. Early Childhood Education Journal, 30, 67-72.

Cornman, D. H., Schmiege, S. J., Bryan, A., Benziger, T. J., \& Fisher, J. D. (2007). An information-motivation-behavioral skills (IMB) model-based HIV prevention intervention for truck drivers in India. Social Science \& Medicine, 64(8), 1572-1584. 
Dancy, N. C., \& Dutcher, G. A. (2007). HIV/AIDS information outreach: A community-based approach. Journal of the Medical Library Association, 95(3), 323-329.

Davis, K. C., Uhrig, J., Rupert, D., Fraze, J., Goetz, J., \& Slater, M. (2011). Effectiveness of a mass media campaign in promoting HIV testing information seeking among African American women. Journal of Health Communication, 16(9), 1024-1039.

De Walque, D. (2007). How does the impact of an HIV/AIDS information campaign vary with educational attainment? Evidence from rural Uganda. Journal of Development Economics, 84(2), 686-714.

Dervin, B., \& Reinhard, C. L. D. (2007). How emotional dimensions of situated information seeking related to user evaluations of help from sources: an exemplar study informed by sense-making methodology. In D. Nahl \& D. Bilal (Eds.), Information and emotion: the emergent affective paradigm in information behaviour research and theory (pp. 51-84). Medford, NJ: Information Today Inc.

Dube, L. (2005). Insights into the diffusion of HIV/AIDS information in higher education institutions in South Africa. International Information \& Library Review, 37(4), 315327.

Dupas, P. (2011). Do teenagers respond to HIV risk information? Evidence from a field experiment in Kenya. American Economic Journal-Applied Economics, 3(1), 1-34.

Edewor, N. (2010). Access to health information by people living with HIV/AIDS in Nigeria. Library Philosophy \& Practice, 12(2), 1-9.

Emeka, O. (2008). Information issues concerning living with HIV/AIDS, its stigma, discrimination and social justice. American Journal of Epidemiology, 167(11), S81-S81. 
Eriksson, T., Sonesson, A., \& Isacsson, A. (1997). HIV/AIDS - information and knowledge: A comparative study of Kenyan and Swedish teenagers. Scandinavian Journal of Social Medicine, 25(2), 111-118.

Espinoza, H., Sequeira, M., Domingo, G., Amador, J. J., Quintanilla, M., \& de los Santos, T. (2011). Management of the HIV epidemic in Nicaragua: The need to improve information systems and access to affordable diagnostics. Bulletin of the World Health Organization, 89(8), 619-620.

Finset, A. (2012). Why should patients and clinicians talk about emotion? Patient Education and Counseling, 89(1), 1-2.

Fisher, C. M. (2012). Adapting the Information-motivation-behavioral skills model: Predicting HIV-related sexual risk among sexual minority youth. Health Education \& Behavior, 39, 290-302.

Fisher, J. D., Fisher, W. A., Bryan, A. D., \& Misovich, S. J. (2002). Information-motivationbehavioral skills model-based HIV risk behavior change intervention for inner-city high school youth. Health Psychology, 21(2), 177-186.

Flicker, S., Goldberg, E., Read, S., Veinot, T., McClelland, A., Saulnier, P., \& Skinner, H. (2004). HIV-positive youth's perspectives on the Internet and eHealth. Journal of Medical Internet Research, 6(3). Retrieved from http://www.jmir.org.gate.lib.buffalo.edu/2004/3/e32/

Fogel, J. (2007). In response to Kalichman et al. (2006). Internet use and coping among those with HIV/AIDS in a mostly African American sample. Health Psychology, 26(5), 537. 
Fourie, I. (2012). Understanding information behaviour in palliative care: Arguing for exploring diverse and multiple overlapping contexts. Information Research, 17(4). Retrieved from http://0-informationr.net.innopac.up.ac.za/ir/17-4/paper540.html\#.UNA55yJXvro

Froelich, M., \& Vazquez-Alvarez, R. (2009). HIV/AIDS knowledge and behaviour: Have information campaigns reduced HIV infection? The case of Kenya. African Development Review-Revue, 21(1): 86-146.

Goh, D. S. (1993). Effects of HIV AIDS information on attitudes toward aids - A cross-ethnic comparison of college-students. Journal of Psychology, 127, 611-618.

Harris, R., \& Dewdney, P. (1994). Barriers to information: How formal help systems fail battered women. Westport, Connecticut: Greenwood.

Harris, R., Veinot, T., \& Bella, L. (2010). A relational perspective on HIV/AIDS information behaviour in rural Canada. Libri, 60(2), 129-141.

Henderson, S. J., Bernstein, L. B., St. George, D. M., Doyle, J. P., Paranjape, A. S., \& CorbieSmith, G. (2004). Older women and HIV: How much do they know and where are they getting their information? Journal of the American Geriatrics Society, 52, 1549-1553.

Hepworth, M. (2007). Knowledge of information behaviour and its relevance to the design of people-centred information products and services. Journal of Documentation, 63(1), 3356.

Heuttel, K. L., \& Rothstein, W. G. (2001). HIV/AIDS knowledge and information sources among deaf and hearing college students. American Annals of the Deaf, 146(3), 280-286.

Hogan, T. P., \& Palmer, C. L. (2005). Information preferences and practices among people living with HIV/AIDS: results from a nationwide survey. Journal of the Medical Library Association, 93(4), 431-439. 
Holtgrave, D. R. (2002). A framework for gauging the comprehensiveness of governmental HIV prevention programs. Journal of public health management and practice, 8(6), 24-29.

Hong, Y., Li, X., Fang, X., Lin, X., \& Zhang, C. (2011). Internet use among female sex workers in China: Implications for HIV/STI prevention. Aids and Behavior, 15, 273-282.

Hong, Y., Li, X., Mao, R., \& Stanton, B. (2007). Internet use among Chinese college students: Implications for sex education and HIV prevention. Cyberpsychology \& Behavior, 10, 161-169.

Huber, J. T., \& Cruz, J. M. (2000). Information needs and information-seeking behaviors of HIV positive men and women. Medical Reference Services Quarterly, 19(3), 39-48.

Hutchinson, A. B., Begley, E. B., Sullivan, P., Clark, H. A., Boyett, B. C., \& Kellerman, S. E. (2007). Conspiracy beliefs and trust in information about HIV/AIDS among minority men who have sex with men. Jaids-Journal of Acquired Immune Deficiency Syndromes, 45(5), 603-605.

Ilo, P. I., \& Adeyemi, A. (2010). HIV/AIDS information awareness among market women: A study of Olofimuyin Market, Sango-Ota, Ogun State, Nigeria. Library Philosophy and Practice. Retrieved from http://unllib.unl.edu/LPP/ilo-adeyemi.htm

Ingwersen, P., \& Järvelin, K. (2005). The turn: Integration of information seeking and retrieval in context. Dordrecht: Springer.

Järvelin, K., \& Vakkari, P. (1993). The evolution of library and information science 1965 - 1985: A content analysis of journal articles. Information Processing and Management, 29(1), 129-144.

Johnson, J. D., \& Case, D. O. (2012). Health information seeking. New York: Peter Lang. 
Julien, H. (1996). A content analysis of the recent information needs and uses literature. Library \& Information Science Research, 18, 53-65.

Julien, H., \& Given, L. (2003). Faculty-librarian relationships in the information literacy context: A content analysis of librarians' expressed attitudes and experiences. Canadian Journal of Information and Library Science, 27(3), 65-87.

Julien, H., McKechnie, E. F., \& Hart, S. (2005). Affective issues in library and information science systems work: a content analysis. Library \& Information Science Research, 27(4), 453-466.

Julien, H., Pecoskie, J. L., \& Reed, K. (2011). Trends in information behavior research, 19992008: A content analysis. Library \& Information Science Research, 33, 19-34.

Kalichman, S. C. (2007). Health information on the Internet and people living with HIV/AIDS: Information evaluation and coping styles. Health Psychology, 26, 692.

Kalichman, S. C., Benotsch, E. G., Weinhardt, L., Austin, J., Luke, W., \& Cherry, C. (2003). Health-related Internet use, coping, social support, and health indicators in people living with HIV/AIDS: Preliminary results from a community survey. Health Psychology, 22(1), 111-116.

Kalichman, S. C., Cain, D., Cherry, C., Pope, H., Eaton, K., \& Kalichman, M. O. (2005). Internet use among people living with HIV/AIDS: Coping and health-related correlates. AIDS Patient Care and STDs, 19(7), 439-448.

Kalichman, S. C., Cherry, C., Cain, D., Pope, H., Kalichman, M., Eaton, L., ... Benotsch, E. G. (2006a). Internet-based health information consumer skills intervention for people living with HIV/AIDS. Journal of Consulting and Clinical Psychology, 74(3), 545-554.

Kalichman, S. C., Cherry, C., Cain, D., Weinhardt, L. S., Benotsch, E., Pope, H., \& Kalichman, 
M. (2006b). Health information on the Internet and people living with HIV/AIDS: Information evaluation and coping styles. Health Psychology, 25(2), 205-210.

Kalichman, S. C., Cherry, C., White, D., Jones, M., Kalichman, M. O., Detorio, M. A., ... Schinazi, R. F. (2012). Use of dietary supplements among people living with HIV/AIDS is associated with vulnerability to medical misinformation on the internet. AIDS Research and Therapy, 9(1), 1-8.

Kalichman, S. C., Picciano, J. F., \& Roffman, R. A. (2008). Motivation to reduce HIV risk behaviors in the context of the information, motivation and behavioral skills (IMB) model of HIV prevention. Journal of Health Psychology, 13(5), 680-689.

Kalichman, S. C., Rompa, D., DiFonzo, K., Simpson, D., Austin, J., Luke, W., ... Buckles, J. (2001). HIV treatment adherence in women living with HIV/AIDS: Research based on the information-motivation-behavioral skills model of health behavior. The Journal of the Association of Nurses in AIDS Care, 12, 58-67.

Kalichman, S. C., Weinhardt, L., Benotsch, E., \& Cherry, C. (2002). Closing the digital divide in HIV/AIDS care: Development of a theory-based intervention to increase Internet access. Aids Care-Psychological and Socio-Medical Aspects of Aids/Hiv, 14, 523-537.

Kanyengo, C. W. (2010). Information and communication: A library's local response to HIV/AIDS in Zambia. Health Information and Libraries Journal, 27(1), 57-65.

Krippendorf, K. (2013). Content analysis: an introduction to its methodology (3rd ed.). Los Angeles: Sage.

Lau, J. T. F., \& Tsui, H. Y. (2012). Voluntary counselling and testing plus information distribution to reduce HIV-related risk behaviours among Hong Kong male cross-border 
truck drivers: A randomised controlled study. Hong Kong Medical Journal, 18(Suppl 3), 39-41.

Liu, S., Wang, K., Yao, S., Guo, X., Liu, Y., \& Wang, B. (2010). Knowledge and risk behaviors related to HIV/AIDS, and their association with information resource among men who have sex with men in Heilongjiang province, China. BMC Public Health, 10, 250.

Retrieved from http://www.biomedcentral.com/1471-2458/10/250

Lottridge, D., Yu, C., \& Chignell, M. (2012). Measuring the emotional impacts of multimedia eHealth. Reviews of Human Factors and Ergonomics, 56(1), 1947-1951.

Lu, H.-Y., Palmgreen, P. C., Zimmerman, R. S., Lane, D. R., \& Alexander, L .J. (2006). Personality traits as predictors of intentions to seek online information about STDs and HIV/AIDS among junior and senior college students in Taiwan. Cyberpsychology \& Behavior: The Impact of the Internet, Multimedia and Virtual Reality on Behavior and Society, 9(5), 577-583.

Manda, P. A. (2006). HIV/AIDS information flow and access: experiences from Babati district, Tanzania. University of Dar es Salaam Library Journal, 8(1-2), 49-59.

Mansoor, L. L., \& Dowse, R. R. (2007). Written medicines information for South African HIV/AIDS patients: Does it enhance understanding of co-trimoxazole therapy? Health Education Research, 22(1), 37-48.

Marhefka, S. L., Valentin, C. R., Pinto, R. M., Demetriou, N., Winzia, A., \& Mellins, C. A. (2011). "I feel like I'm carrying a weapon." Information and motivations related to sexual risk among girls with perinatally acquired HIV. AIDS Care, 23, 1321-1328. 
Mayben, J. K., \& Giordano, T. P. (2007). Internet use among low-income persons recently diagnosed with HIV infection. Aids Care-Psychological and Socio-Medical Aspects of Aids/Hiv, 19, 1182-1187.

Mill, J. E., Edwards, N., Jackson, R. C., MacLean, L., \& Chaw-Kant, J. (2010). Stigmatization as a social control mechanism for persons living with HIV and AIDS. Qualitative Health Research, 20(11), 1469-1483.

Mo, P., \& Coulson, N. (2008). Testing a model of health-related internet use and disease coping among individuals living with HIV/AIDS. International Journal of Psychology, 43(3-4), 413.

Mosha, N. F. M., \& Manda, P. (2012). HIV/AIDS information and changing sexual behaviour among undergraduate students in Tanzania. Aslib Proceedings: New Information Perspectives, 64(5), 509-518.

Nahl, D. (2007). Introduction. In D. Nahl \& D. Bilal (Eds.), Information and emotion: The emergent affective paradigm in information behavior research and theory ( $\mathrm{pp} . \mathrm{xvii}$ xxix). Medford, NJ: Information Today.

Nahl, D., \& Bilal, D. (Eds.). (2007). Information and emotion: The emergent affective paradigm in information behavior research and theory. Medford, NJ: Information Today.

Nokes, K. M., \& Nwakeze, P. C. (2005). Assessing self-management information needs of persons living with HIV/AIDS. AIDS Patient Care and STDs, 19(9), 607-613.

Ntombela, M., Stilwell, C., \& Leach, A. (2008). Hello tomorrow? Sources of HIV/Aids information used by residential students at the University of Natal. South African Journal of Library \& Information Science, 74, 73-82. 
Nwezeh, C. M. T. (2008). A survey of information sources used by secondary school students in Ife Central and Ife East local government areas of Osun State, Nigeria for knowledge and attitudes towards HIV/AIDS. Journal of Hospital Librarianship, 8(4), 383-397.

Odusanya, O. K., \& Bankole, O. M. (2006). A survey of information sources used by secondary school students on Ogun State, Nigeria for knowledge and attitudes towards HIV/AIDS. African Journal of Library, Archives \& Information Science, 16(1), 53-63.

Petros, S. G. (2012). Use of a mixed methods approach to investigate the support needs of older caregivers to family members affected by HIV and AIDS in South Africa. Journal of Mixed Methods Research, 6(4), 275-293.

Polinko, P., Bradley, W. F., Molyneaux, B., Lukoff, C., \& Erlen, J. (1995). HIV in health-care workers - managing fear through a telephone information line. Social Work, 40, 819-822.

Preece, J. (2007). Forward. In D. Nahl \& D. Bilal (Eds.), Information and emotion: The emergent affective paradigm in information behavior research and theory (pp. $\mathrm{xv}$-xvi). Medford, NJ: Information Today.

Reeves, P. M. (2000). Coping in cyberspace: The impact of Internet use on the ability of HIVpositive individuals to deal with their illness. Journal of Health Communication, 5, 4759.

Reeves, P. M. (2001). How individuals coping with HIV/AIDS use the Internet. Health Education Research, 16, 709-719.

Rice, E., Monro, W., Barman-Adhikari, A., \& Young, S. D. (2010). Internet use, social networking, and HIV/AIDS risk for homeless adolescents. Journal of Adolescent Health, 47, 610-613. 
Robinson, C., \& Graham, J. (2010). Perceived Internet health literacy of HIV-positive people through the provision of a computer and Internet health education intervention. Health Information and Libraries Journal, 27, 295-303.

Samal, L., Saha, S., Chander, G., Korthuis, P. T., Sharma, R. K., Sharp, V., ... Beach, M. C. (2011). Internet health information seeking behavior and antiretroviral adherence in persons living with HIV/AIDS. AIDS Patient Care and STDs, 25(7), 445-449.

Sandstrom, K. L. K. (1996). Searching for information, understanding, and self-value: the utilization of peer support groups by gay men with HIV/AIDS. Social Work in Health Care, 23(4), 51-74.

Schmidt, S., \& Stock, W. G. (2009). Collective indexing of emotions in images. A study in emotional information retrieval. Journal of the American Society for Information Science and Technology, 60(5), 863-876.

Schnall, R., Cimino, J. J., \& Bakken, S. (2012). Development of a prototype continuity of care record with context-specific links to meet the information needs of case managers for persons living with HIV. International Journal of Medical Informatics, 81, 549-555.

Schnall, R., Cimino, J. J., Currie, L. M., \& Bakken, S. (2011). Information needs of case managers caring for persons living with HIV. Journal of the American Medical Informatics Association, 18(3), 305-308.

Sheih, C. S.-M. (2011). A study of readers' negative emotions in university libraries. Journal of Library and Information Studies, 9(1), 77-121.

Shelley, G. A., Killworth, P. D., Bernard, H. R., McCarty, C., Johnsen, E. C., \& Rice, R. E. (2006). Who knows your HIV status II?: Information propagation within social networks of seropositive people. Human Organization, 65(4), 430-444. 
Smith, K. (2011). Anxiety, knowledge and help: A model for how Black and White college students search for HIV/AIDS information on the Internet. Qualitative Report, 16, 103125.

Smith, L. A. (2004). Internet use among people with HIV/AIDS. Journal of Technology in Human Services, 22(2), 17-29.

Stroman, C. A. (2005). Disseminating HIV/AIDS information to African Americans. Journal of Health Care for the Poor and Underserved, 16(4), 24-37.

Sun, X., Lu, F., Wu, Z., Poundstone, K., Zeng, G., Xu, P., ... Liau, A. (2010). Evolution of information-driven HIV/AIDS policies in China. International Journal of Epidemiology, 39, II4-III3.

Swartz, L., \& Roux, N. (2004). A study of local government HIV/AIDS projects in South Africa. SAHARA J: Journal of Social Aspects of HIV/AIDS Research Alliance, 1(2), 99-106.

Tawilah, J., Tawil, O., Bassiri, S., \& Ziady, H. (2002). Information needs assessment for HIV/AIDS and STIs in the Eastern Mediterranean Region. Eastern Mediterranean Health Journal, 8, 689-698.

Tenopir, C. (1994). Online databases: The emotions of searching. Library Journal, 119(14), 134134.

Thelwall, M., Wilkinson, D., \& Uppal, S. (2010). Data mining emotion in social network communication: Gender differences in MySpace. Journal of the American Society for Information Science and Technology, 61(1), 190-199.

Uhegbu, A. N., \& Okereke, C. I. (2006). Decades of persistent ignorance towards sustainable dissemination of HIV/AIDS information among rural women in Imo State, Nigeria. Library Review, 55(1), 35-44. 
Veinot, T. C. (2009). Interactive acquisition and sharing: Understanding the dynamics of HIV/AIDS information networks. Journal of the American Society for Information Science and Technology, 60(11), 2313-2332.

Veinot, T. (2010). A multilevel model of HIV/AIDS information/help network development. Journal of Documentation, 66(6), 875-905.

Veinot, T., Harris, R., Bella, L., Krajnak, J., \& Rootman, I. (2006). HIV/AIDS information exchange in rural communities: Preliminary findings from a three-province study. Canadian Journal of Information and Library Science, 30(3/4), 271-290.

Wetherell, M. (2012). Affect and emotion: A new social science understanding. London: Sage.

White, M. D., \& Marsh, E. E. (2006). Content analysis: A flexible methodology. Library Trends, $55(1), 22-45$.

Wilson, T. D. (1999). Models in information behaviour research. Journal of Documentation, 55(3), 249-270.

Yazdi, C. A., Aschbacher, K., Arvantaj, A., Naswer, H. M., Abdollahi, E., Asadi, A., ... Moghadam, A. K. (2006). Knowledge, attitudes and sources of information regarding HIV/AIDS in Iranian adolescents. AIDS Care, 18(8), 1004-1010.

Ybarra, M. L., Kiwanuka, J., Emenyonu, N., \& Bangsberg, D. R. (2006). Internet use among Ugandan adolescents: Implications for HIV intervention. Plos Medicine, 3, 2104-2112. Yousafzai, A. K., Edwards, K., D'Allesandro, C., \& Lindstrom, L. (2005). HIV/AIDS information and services: The situation experienced by adolescents with disabilities in Rwanda and Uganda. Disability and Rehabilitation, 27(22), 1357-1363. 